\title{
Estimation of microalgal biomass and oil productivity potential in South America by climate-simulated culturing
}

\author{
${\text { Camila } \text { Coronel }^{1} \text { and LEONARDO CURATTI }}^{2}$ \\ ${ }^{1}$ Argentina Ministry of Science Technology and Innovation \\ ${ }^{2}$ Argentina Ministerio de Ciencia Tecnología e Innovación
}

February 23, 2021

\begin{abstract}
Current production costs of microalgal biomass indicate that only highly-productive cultivation facilities will approach commercial feasibility. Geographical site selection for siting those facilities is critical for achieving target productivities. The aim of this study was to provide a semi-empirical estimation of microalgal biomass and lipids productivity in South America. Simulated-climate was programed in environmental photobioreactors (PhenometricsTM) for a simulation of cultivation in open raceway ponds at different geographical sites. The mean annual South American biomass productivity of 20-cm deep ponds was $12 \pm 4 \mathrm{~g} \cdot \mathrm{m}-2 \cdot \mathrm{d}-1$. The most productive regions were clustered in the subtropical and tropical regions of the continent. Fortaleza (Brazil) showed a low seasonality and a high annual mean productivity of $23 \mathrm{~g} \cdot \mathrm{m}-2 \cdot \mathrm{d}-1$ in 5 -cm deep ponds. Lipids accumulation and productivity in Fortaleza showed a high microalgal oil accumulation up to $46 \%$ (w/w) and a maximum oil productivity of $5 \mathrm{~g} \cdot \mathrm{m}-2 \cdot \mathrm{d}-1$ for biomass containing around $20 \%$ lipids (w/w). This study provides the first semi-empirical estimation of microalgal productivity in South America and supports a high potential of a vast region of the continent.
\end{abstract}

\section{Introduction}

Access to affordable and clean energy is one of the Sustainable Development Goals of the United Nations towards $2030^{[1]}$. Biomass is a primary source of energy for more than 2 billion people in developing countries. Besides the direct impact of increased access to clean energy, biomass-based industry represents an increasing source of jobs and income in poor rural areas, contributing significantly to well-being and development ${ }^{[2,3]}$.

Microalgae are claimed as a promising alternative feedstock for biofuels, feed, food and chemical precursors due to a higher conversion efficiency of solar-to-chemical energy than terrestrial crops ${ }^{[4]}$. An estimation indicated that cultivation of 406 million ha of microalgae producing biomass at $10 \mathrm{~g} \cdot \mathrm{m}^{-2} \cdot \mathrm{d}^{-1}$ with an oil content in the biomass of $30 \%(\mathrm{w} / \mathrm{w})$ would be enough to fulfill the global fuel demand ${ }^{[4]}$. This productivity would be about 27-fold higher than that of soybean, one of the main current feedstocks for biodiesel [4,5]. Additionally, microalgae can be cultivated on non-arable land, in brackish or seawater, and can take industrial and/or domestic waste as a source of nutrients/fertilizers ${ }^{[6]}$, including $\mathrm{CO}_{2}$ from point sources of flue gas for additional benefits of $\mathrm{C}$ capture and recycling[${ }^{[7]}$.

However, given the available technology for microalgal biomass production, only high-value products, such as carotenoids and algal biomass for aquaculture feed, have commercial potential in the short term [8-10]. Conversely, most techno-economic analyses indicated that for the production of biofuels from microalgal biomass, costs must be substantially reduced for commercial feasibility ${ }^{[8-10]}$. Regardless of the generally higher biomass productivity of microalgae in comparison with terrestrial crops, the currently high fixed expenses (construction and operation of cultivation facilities) make the algal biomass cost very sensitive to year-round productivity. For example, pioneering techno-economic analyses suggested that a $50 \%$ increase in productivity, from 20 to $30 \mathrm{~g} \cdot \mathrm{m}^{-2} \cdot \mathrm{d}^{-1}$, would result in a $19 \%$ reduction in the cost of the algal biomass ${ }^{[8,11]}$. 
Most literature survey analyses indicated that the empirically achieved values for microalgal productivity in raceway ponds were $10-15 \mathrm{~g} \cdot \mathrm{m}^{-2} \cdot \mathrm{d}^{-1}$ based on sustained values averaged over the course of a year [8,9,12-15]. However, the National Renewable Energy Laboratory - U.S. Department of Energy (NREL-DOE; US) estimated an algal biomass productivity threshold of at least $25 \mathrm{~g} \cdot \mathrm{m}^{-2} \cdot \mathrm{d}^{-1}$ for an algal biomass production cost of $\$ 0.54 \cdot \mathrm{kg}^{-1}$, that would enable cost-effective biofuel production from algal biomass towards $2022^{[15,16]}$. The demonstration of a year-round mean productivity of microalgal biomass containing $40 \%(\mathrm{w} / \mathrm{w})$ lipids of $23 \mathrm{~g} \cdot \mathrm{m}^{-2} \cdot \mathrm{d}^{-1}$ in a production plant operated in Hawaii ${ }^{[13]}$ supports the achievability of the DOE's target, at least in selected locations of the world.

Modeling algal productivity potential is a fundamental aspect of resource assessment analyses for identifying those likely high-productivity sites as a critical part of techno-economic analyses, which are intended to minimize the risk of investments for siting algae production facilities for biofuels. However, extrapolation from laboratory-scale data and oversimplification of strain specific biological responses led to a large uncertainty in the results, and frequently in the overestimation of algal productivity ${ }^{[13,17,18]}$. The model proposed by Moody and colleagues suggested an average world productivity ofNannochloropsis of $9.4 \mathrm{~g} \cdot \mathrm{m}^{-2} \cdot \mathrm{d}^{-1}$ and up to $15 \mathrm{~g} \cdot \mathrm{m}^{-2} \cdot \mathrm{d}^{-1}$ in developing regions of the world such as South America, Africa and India ${ }^{[18]}$. Despite these mathematical models suggested that climate conditions would favor implementation of highly productive algal biomass facilities in these regions, $\mathrm{R} \& \mathrm{D}$ efforts in developing countries lag behind those in more developed regions of the world ${ }^{[2,19-22]}$.

A high annual average productivity is frequently limited by the degree of variation between seasons of high and low productivity ${ }^{[14]}$. A reference techno-economic analysis predicted that shortening the annual growth period from 300 to 250 days would increase the cost of algal biomass by $33 \%^{[8]}$. Light and temperature are the main abiotic determinants of microalgal biomass productivity. Thus, seasonal variability at different geographical sites represents a major limitation for high mean annual productivity and biomass production cost at those locations ${ }^{[8,9,12-15]}$. A harmonized model presented by the NREL-DOE for Chlorella sorokiniana (DOE 1412) cultivated along the U.S. Gulf Coast during 2012-2013 assumed a productivity ratio of 5:1 between summer and winter. The same report set a target of 3:1 to be accomplished by 2022, either by rotation of different strains and/or genetic engineering ${ }^{[14]}$.

More recently, the implementation of devices for climate-simulated conditions for microalgal cultivation in open ponds such as those at the Pacific Northwest National Laboratory ${ }^{[23]}$, or the Phenometrics Environmental Photobioreactors (ePBRs) ${ }^{[24]}$, brought a low-risk and cost-effective way of semi-empirical estimation of algal productivity at any specific geographic location. Thus, the cultivation of C. sorokiniana (DOE 1412) under climate-simulated conditions in open ponds during three seasons in Southern Florida indicated an average year-round biomass productivity of $15 \mathrm{~g} \cdot \mathrm{m}^{-2} \cdot \mathrm{d}^{-1}$ and a lower seasonal variability, with a productivity ratio of 1.7:1 between summer and winter ${ }^{[25]}$.

Another recent study aimed at estimating the maximum achievable productivity of Scenedesmus obliquus in Brazilian simulated-climate in photobiorreactors showed higher biomass and lipid productivity in the most tropical areas of the country ${ }^{[26]}$.

The goal of the present study was to provide an estimation of biomass and oil productivity of S. obliquus in open raceway ponds under South America simulated-climate. The study also simulated different pond's depth, $\mathrm{CO}_{2}$ supplementation and seasonal variation in algal productivity at different geographical sites. Results support a high potential of most subtropical and tropical regions of the continent.

\section{Results}

\subsection{Simulation of $S$. obliquus sp. C1S biomass productivity in different ecoregions of South} America

Previous studies suggested that the average algal productivity in summer (high productivity season) and winter (low productivity season) could be a good estimator of average annual productivity in any region ${ }^{[14,25]}$. To further confirm the appropriateness of this simplification, we calculated the $S$. obliquus average productiv- 
ity of biomass, lipids or carbohydrates in the four seasons in Buenos Aires, La Quiaca, Posadas (Argentina) and Fortaleza (Brazil) and compared them against the average values considering only summer and winter (Figure S1, Supporting information). Strong positive correlations $(r=0.86 ; 0.87$; or $0.96 ; \mathrm{P}<0.0001$, for biomass, carbohydrates or lipids, respectively) suggested that a simplified model based on summer and winter productivities would provide a good estimation for mean annual productivities across a broad range of simulated-climates.

Figure 1 shows the average summer and winter biomass productivity in 20-cm deep simulated ponds of cultures supplemented with $\mathrm{CO}_{2}$. The calculated mean annual productivities were $16.76 \pm 1.88 ; 13.72 \pm$ $3.11 ; 13.03 \pm 1.39 ; 10.61 \pm 2.43 ; 10.56 \pm 3.70 ;$ and $7.36 \pm 4.48 \mathrm{~g} \cdot \mathrm{m}^{-2} \cdot \mathrm{d}^{-1}$ in Fortaleza (Brazil), Paita (Peru), Caracas (Venezuela), Posadas, Buenos Aires, and Comodoro Rivadavia (Argentina), respectively. The overall mean annual productivity in South America was $12 \pm 4 \mathrm{~g} \cdot \mathrm{m}^{-2} \cdot \mathrm{d}^{-1}(n=24)$.

Seasonal variability between summer and winter was lower in Tropical and Subtropical regions for summer to winter productivity ratios of $1.2: 1 ; 1.4: 1 ; 1.2: 1 ; 1.5: 1$ in Fortaleza, Paita, Caracas, Posadas, respectively.

Our simulations suggest potential biomass productivities in summer, from $18.25 \pm 0.54 \mathrm{~g} \cdot \mathrm{m}^{-2} \cdot \mathrm{d}^{-1}$ to 11.24 $\pm 0.2 \mathrm{~g} \cdot \mathrm{m}^{-2} \cdot \mathrm{d}^{-1}$ in Fortaleza (the highest in this study) and Comodoro Rivadavia (the lowest in this study), respectively and a large seasonality and low productivity in winter in Comodoro Rivadavia (3.49 \pm $\left.0.04 \mathrm{~g} \cdot \mathrm{m}^{-2} \cdot \mathrm{d}^{-1}\right)$.

Under nutrient-sufficient and short-cycle cultivation conditions, S. obliquus only presented low levels of lipids at $13.4 \pm 2.9 \%(\mathrm{w} / \mathrm{w})$ across these simulations. Only a minor increase in lipids accumulation was observed in the coldest condition analyze, which corresponded to Comodoro Rivadavia winter simulated-climate, at $22.57 \pm 0.23 \%(\mathrm{w} / \mathrm{w})$. Carbohydrates also remained at low levels across the study at about $29.3 \pm 13.1 \%$ $(\mathrm{w} / \mathrm{w})$ and a mild tendency to increase in warmer conditions at $32.1 \pm 2.7 \%$ and $34.4 \pm 4.4 \%$, in the summer simulated- climate of Paita and Fortaleza, respectively (Table S1, Supporting information).

\subsection{Effect of $\mathrm{CO}_{2}$ supplementation and seasonality on microalgal productivity simulated-} climate of different regions

Considering that flue gas availability could limit the achievement of maximum algal biomass potential in some regions of South America, we determined the effect of not supplementing $\mathrm{CO}_{2}$ onS. obliquus on productivity in simulated-climate of Buenos Aires, Posadas and Fortaleza. Lack of $\mathrm{CO}_{2}$ supplementation lessened annual mean biomass productivity from $10,56 \pm 1,85 \mathrm{~g} \cdot \mathrm{m}^{-2} \cdot \mathrm{d}^{-1}$ to $4,71 \pm 0,89 \mathrm{~g} \cdot \mathrm{m}^{-2} \cdot \mathrm{d}^{-1}$ (55\% lower) in Buenos Aires; from $10,61 \pm 1,21 \mathrm{~g} \cdot \mathrm{m}^{-2} \cdot \mathrm{d}^{-1}$ to $5,18 \pm 0,78 \mathrm{~g} \cdot \mathrm{m}^{-2} \cdot \mathrm{d}^{-1}(51 \%$ lower $)$ in Posadas; and from $16,76 \pm 0,94 \mathrm{~g} \cdot \mathrm{m}^{-2} \cdot \mathrm{d}^{-1}$ to $7,14 \pm 0,70 \mathrm{~g} \cdot \mathrm{m}^{-2} \cdot \mathrm{d}^{-1}(57 \%$ lower $)$ in Fortaleza. The same level of reduction of biomass productivity was observed in summer and winter if $\mathrm{CO}_{2}$ is was not supplied (Figure 2).

Cultures not-supplemented with $\mathrm{CO}_{2}$ consistently presented slightly higher levels of carbohydrates and lipids in their biomass. However, both carbohydrates and lipids productivity was largely offset by the slower growth rate of these cultures (Figure 3).

\subsection{Effect of seasonality and cultures' depth on microalgal productivity in Fortaleza simulated- climate}

In open raceway ponds, microalgae are exposed to a complex light environment. In addition to changes in sunlight intensity throughout the day and the seasons, as the culture reaches higher cell densities, light gradients occur within the water column and cells are exposed to different light intensities and short light cycles, depending on mixing efficiency ${ }^{[17]}$. This effect could be quite successfully simulated in our experimental system. Figure 4a shows a representative front view of the ePBR vessels for simulations of $S$. obliquus C1S in 20-cm deep ponds at the inoculation time $\left(\mathrm{OD}_{750}=0.3\right)$; at a later time $\left(\mathrm{OD}_{750}=1.5\right)$; or simulations of $5-\mathrm{cm}$ deep ponds at the same $\mathrm{OD}_{750}$ of 1.5 , when all cultures were exposed to the same light intensity of $1,719 \mu \mathrm{mol}$ photons $\cdot \mathrm{m}^{-2} \cdot \mathrm{s}^{-1}$ at the surface of the water column. In Fortaleza simulated-climate, S. obliquus growth rate increased in simulated shallower ponds (Figure $4 \mathrm{~b}$ ), which resulted in a proportional increase in the volumetric biomass productivity of the cultures (Figure 4c). While volumetric productivity remained 
similar for summer and winter simulated-climate in 20- and 10-cm deep ponds, it resulted consistently higher in winter than in summer simulated-climate for 5-cm deep ponds (Figure 4c). As expected, a volume increase in deeper ponds compensated for the slower growth rate and similar areal productivities in both seasons in 20 - or 10-cm deep ponds and in summer in 5 -cm ponds were observed. However, increased growth rate in 5 -cm ponds in winter resulted in a higher areal productivity of $26.22 \pm 1.23 \mathrm{~g} \cdot \mathrm{m}^{-2} \cdot \mathrm{d}^{-1}$. The calculated annual mean productivities were $16.79 \pm 1.92 \mathrm{~g} \cdot \mathrm{m}^{-2} \cdot \mathrm{d}^{-1} ; 17.77 \pm 0.97 \mathrm{~g} \cdot \mathrm{m}^{-2} \cdot \mathrm{d}^{-1} ;$ and $23.01 \pm 3.21 \mathrm{~g}$. $\mathrm{m}^{-2} \cdot \mathrm{d}^{-1}$, in $20-, 10-$, or 5 -cm ponds, respectively.

Interestingly, the low seasonality of biomass productivity determined for 20 -cm ponds in Fortaleza, for a summer-to-winter ratio of 1.2, was further improved, and even reversed, in 10- and 5-cm ponds, for summerto-winter ratios of 0.93 and 0.77 , respectively.

\subsection{Optimization of lipids accumulation and productivity in shallow ponds in Fortaleza simulated-climate}

Short cultivation cycles under nutrients replete conditions, resulted in low accumulation levels of lipids (Table S1, Supporting information and Figures 3 and 5). Thus, to analyze the impact of nutrients depletion on lipids productivity, we simulated cultures of $S$. obliquus $\mathrm{C} 1 \mathrm{~S}$ supplemented with $2 \% \mathrm{CO}_{2}(\mathrm{v} / \mathrm{v})$ and $6 \mathrm{mM}$ $\mathrm{NaNO}_{3}$ in 5 -cm deep ponds in Fortaleza, in winter, in longer cultivation cycles. These cultures reached the stationary phase of growth in 3 days (Figure 6a) and a biomass concentration of $2 \mathrm{~g} \cdot \mathrm{L}^{-1}$. The biomass became enriched in lipids from an initial value of less than $10 \%(\mathrm{w} / \mathrm{w})$ to $20 \%(\mathrm{w} / \mathrm{w})$ at the onset of the stationary phase and continued increasing up to a final value of $46 \%(\mathrm{w} / \mathrm{w})$ at the $7^{\text {th }}$ day of culture (Figure $6 \mathrm{~b})$. The analysis of the time course of areal biomass productivity showed a maximum value around the second day (Figure 6c). Conversely, the maximum lipid productivity resulting from cell proliferation and the induction of lipid accumulation presented a relatively constant value around $5 \mathrm{~g} \cdot \mathrm{m}^{-2} \cdot \mathrm{d}^{-1}$ between days 2 and 5 of culture (Figure $6 \mathrm{~d}$ ).

\section{Discussion}

\subsection{Simulation of $S$. obliquus sp. C1S biomass productivity in different ecoregions of South America}

The geographical sites for simulations of microalgal potential productivity in this study were chosen to cover a broad range of mean irradiation, temperature and day length (Table 1 and Figure S2, Supporting information). This study prioritized coastal areas with potential access to seawater, considering that tropical and subtropical forests provide essential ecosystem services including natural biodiversity conservation and global climate change mitigation ${ }^{[27]}$ (Figure S3, Supporting information).

The overall mean annual productivity in South America of $12 \pm 4 \mathrm{~g} \cdot \mathrm{m}^{-2} \cdot \mathrm{d}^{-1}$ fits very well previous estimations in other studies, regardless of differences in the strains used and culture systems. For example, extensive literature analyses performed by other researchers indicated that most commonly achieved annual productivities in raceway ponds in different regions of the world were $10-15 \mathrm{~g} \cdot \mathrm{m}^{-2} \cdot \mathrm{d}^{-1[8,9,12-15]}$. The model proposed by Moody and colleagues suggested an average world productivity of $9.4 \mathrm{~g} \cdot \mathrm{m}^{-2} \cdot \mathrm{d}^{-1}$ for Nannochloropsis cultivated in photobioreactors, and up to $15 \mathrm{~g} \cdot \mathrm{m}^{-2} \cdot \mathrm{d}^{-1}$ in Brazil, Colombia and other non-South American regions [18]. Another study assessing the productivity of C. sorokiniana (DOE 1412) under climate-simulated conditions of Southern Florida indicated an average year-round biomass productivity of $15 \mathrm{~g} \cdot \mathrm{m}^{-2} \cdot \mathrm{d}^{-1}[25]$. A more recent estimation of $S$. obliquus biomass productivity in photobiorreactors under Brazilian simulated-climate indicated a higher productivity of the Tropical Northern region of the country (Boa Vista) with an annual mean biomass productivity of $0.278 \pm 0.01 \mathrm{~g} \cdot \mathrm{L}^{-1} \cdot \mathrm{d}^{-1[26]}$.

We observed very low seasonal variability in biomass productivity in Tropical and Subtropical regions. The recent study by Siqueira and colleagues for S. obliquus biomass productivity under simulated-climate conditions of Northern Brazil indicated a low summer to winter productivity ratio of $1.3: 1^{[26]}$. This low seasonality would allow an almost year-round steady production in this vast region, surpassing NREL-DOE target of summer to winter productivity ratio of $3: 1^{[14]}$. The productivities estimated in this simulations 
would enable some commercial feasibility, after due optimizations and practical demonstrations on site. However, a large seasonality and low productivity in winter (i.e. $3.49 \pm 0.04 \mathrm{~g} \cdot \mathrm{m}^{-2} \cdot \mathrm{d}^{-1}$ in Comodoro Rivadavia) would pose a difficult-to-overcome limitation for year-round high productivity in the Southern part of the continent. Both, a similar low level accumulation of lipids [12.4 $-17.0 \%(\mathrm{w} / \mathrm{w})]$ and mild increase at lower temperatures in $S$. obliquus was also observed in a parallel study by Siqueira and colleagues ${ }^{[26]}$.

\subsection{Effect of $\mathrm{CO}_{2}$ supplementation and seasonality on microalgal productivity simulated- climate of different regions}

Atmospheric concentration of $\mathrm{CO}_{2}$ and its diffusion into water normally limit the maximum phototrophic growth rate and biomass productivity of $S$. obliquus ${ }^{[28]}$ and most microalgae ${ }^{[29]}$. It was estimated that to achieve a biomass productivity of $25 \mathrm{~g}$ [?] $\mathrm{m}^{-2}$ [?] $\mathrm{d}^{-1}$, a minimum of $46 \mathrm{~g}$ [?] $\mathrm{m}^{-2}$ [?] $\mathrm{d}^{-1}$ of $\mathrm{CO}_{2}$ must be dissolved in the culture medium to avoid its limitation on biomass productivity ${ }^{[30]}$. Although the cost of raw materials represents a low fraction of algal biomass production cost in comparison with facilities, machinery and labor, $\mathrm{CO}_{2}$ is currently the main contributory factor to utility costs ${ }^{[10,29]}$. The utilization of flue gas from industrial waste as a source of $\mathrm{CO}_{2}$ is likely the best available alternative ${ }^{[29]}$. However, the logistics related to availability, management and transportation imposes additional costs. Resource assessment analysis suggested that access to flue gas by transportation from emission sources located 4.8 $\mathrm{km}$ or $80 \mathrm{~km}$ from the microalgae farm in the US would render 44 or 1,800 million barrels of oil equivalent, respectively. Being the latter option clearly not economically competitive ${ }^{[29]}$. A comparatively lower valueadded industrialization in South America ${ }^{[31,32]}$, is correlated with a lower production of $\mathrm{CO}_{2}$ as an industrial waste ${ }^{[33]}$.

Lack of $\mathrm{CO}_{2}$ supplementation lessened annual mean biomass productivity more than $50 \%$ mostly regardless of the geographical site. A similar study aimed at studying the influence of $\mathrm{CO}_{2}$ supplementation on $S$. obliquus outdoors cultivation in 2.6- to 4.4-cm deep open thin-layer cascade systems in Belgium in summer showed that biomass productivity dropped to $46 \%$ of that of the $\mathrm{CO}_{2}$-supplemented cultures (56\% lower $)^{[28]}$. Taken together, regardless of differences in the culture systems, these studies tend to indicate the need for $\mathrm{CO}_{2}$ supplementation to boost biomass productivity about two-fold, which otherwise would leave biomass productivity quite far away from productivity targets for commercial feasibility ${ }^{[15]}$.

\subsection{Effect of seasonality and cultures' depth on microalgal productivity in Fortaleza simulated- climate}

Interestingly, no seasonality in biomass productivity was observed in the Northeastern region of the continent, especially in the more shallow simulated-ponds (10- and 5-cm deep). Conversely to most other sites analyzed in this study (Table 1 and Figure S2, Supporting information), and other worldwide reference sites for high microalgal productivity (Figure S4, Supporting information), in Fortaleza, and to a lesser extent in Caracas, increased raining and overcast days in the summer months result in less shiny days than in winter and spring. These results support the notion that, in addition to season-specific strains ${ }^{[14]}$, season-specific optimization of culture conditions might have a positive impact on year-round productivity.

Results presented herein for climate-simulated shallow cultures of $S$. obliquus fit very well with a previous outdoors cultivation study that used 2.6- to 4.4-cm deep open thin-layer cascade systems in Belgium in summer (irradiation of $1,500-1,700 \mu \mathrm{mol}$ photons $\cdot \mathrm{m}^{-2} \cdot \mathrm{s}^{-1}$ and $25 \pm 5{ }^{\circ} \mathrm{C}$ ) which showed a biomass productivity of $24 \mathrm{~g} \cdot \mathrm{m}^{-2} \cdot \mathrm{d}^{-1}{ }^{[28]}$. Another study using a dynamic climate simulation for the cultivation of $N$. salina in thin-layer cascade systems under the summer climate of Almería, Spain, as a reference location for high productivity of outdoors cultivation of microalgae, also showed an areal biomass productivity of $25 \mathrm{~g} \cdot \mathrm{m}^{-2} \cdot \mathrm{d}^{-1[34]}$. Taken together, these studies indicated that, under favorable climate conditions, areal biomass productivities around $25 \mathrm{~g} \cdot \mathrm{m}^{-2} \cdot \mathrm{d}^{-1}$ are achievable in shallow ponds or thin-layer cascades either in true outdoors cultivation trials or under simulated-climate. This convergence of results is important for the validation of devices for the estimation of biomass productivity under conditions of simulated-climate, and also because productivity approaches the target towards commercially competitive production of microalgal biomass ${ }^{[15]}$. 
An evaporation rate of $5-7 \mathrm{~L} \cdot \mathrm{m}^{-2} \cdot \mathrm{d}^{-1}$ in shallow ponds and cascade systems operated under warm and dry conditions represents a challenging aspect of these cultivation systems ${ }^{[34]}$. Thus, even though these systems can be initially based on seawater, substantial amounts of freshwater would be needed to keep salinity within the microalgae cultivation range. This would be especially critical in Fortaleza because of its characteristic annual rainfall regime and the overlapping between the dry season and that of the highest biomass productivity potential. An elegant approach was proposed for collecting rainwater using the channel of thin-layer systems while storing the algae suspension in a tank ${ }^{[34]}$. Specifically dedicated resource-assessment and full techno-economic analyses are needed to evaluate whether long-term storage of rainwater would be feasible in Fortaleza.

\subsection{Optimization of lipids accumulation and productivity in shallow ponds in Fortaleza simulated-climate}

Although we demonstrated in this study a high level of lipids accumulation at $46 \%(\mathrm{w} / \mathrm{w})$ at the $7^{\text {th }}$ day of culture, the highest productivity was observed from day 3 to 5 , at a lipids content in the biomass from $20 \%$ to $35 \%(\mathrm{w} / \mathrm{w})$, respectively. Thus, a harvesting time around the $5^{\text {th }}$ day, at twice the time for maximum biomass productivity, would be recommended for lipids as the main target product, because accumulation in the biomass could provide an advantage for product recovery ${ }^{[35]}$. However, if other co-products (carbohydrates and/or proteins) could be isolated in a biomass biorefinery ${ }^{[15,20]}$, it is possible that an earlier biomass collection could be more advantageous.

\subsection{Strengths and limitations of ePBRs for biomass productivity estimation}

This study further supports the convenience of using commercially available devices such as ePBRs for low cost and low risk assessment of potential microalgal productivity on any geographical region and to contribute information on the effect of cultivation variables with high resolution of site and season specificity. This is especially important for advancing R\&D of microalgal biotechnology in developing countries. This is mostly because the costs of installation and operation of raceway ponds, even being the least expensive cultivation systems, might still represent a barrier to accelerate R\&D in developing countries. Thus, both mathematical modeling $[18,36]$ and devices for productivity estimation under climate simulated conditions are generally valuable ${ }^{[23,26]}$ and especially useful to optimized limited resourced allocated to $R \& D$ in developing counties $[2,19,22]$.

As commented before ${ }^{[23,37]}$ ePBRs proved to be highly reliable in terms of producing very consistent results with low variation among independent runs after randomizing the scripts and the ePBR units.

On the other side, a validation study by Huesemann and colleagues (2017) suggested that Phenometrics ${ }^{\text {TM }}$ ePBRs might underestimate microalgal biomass productivity up to $44 \%$ for C. sorokiniana (DOE 1412) in Arizona (US) simulated-climate. Similarly, the optical-density-based biomass productivity and the rate of increase in cell counts of Picochlorum soloecismus in the ePBRs was also lower than in custom-built PNNL indoor climate-simulation ponds ${ }^{[23]}$. It is currently unknown whether ePBRs generally underestimate microalgal biomass productivity and/or if the inaccuracy could be strain specific. Although this raises some uncertainties on the absolute productivity potential of the geographical sites analyzed in this study, and others, it tends to provide an optimistic base-line for a comparative estimation. Additionally, it is important to take into account that these simulations oversimplify the complexity of outdoors cultivation of microalgae for weather homogenization around historical annual averages of temperature and irradiation. Overriding year specific climatic fluctuations might give reasonably accurate predictions of microalgal biomass productivity in the long-term. However, weather fluctuations at different time scales (from hours to years) should be tolerated by selected robust strains to make both short- and long-term predictions more realistic. Robustness of selected strains should also prevent and/or tolerate contamination, predation and/or grazing for more realistic predictive models.

As concluding remarks, this study represents a pioneering work for the estimation of microalgal biomass productivity in South America. Results support a high potential of Tropical and Subtropical regions for high biomass productivities. Fortaleza (Brazil) was identified as one of the candidate production sites with a 
predicted annual average biomass productivity of $23 \mathrm{~g} \cdot \mathrm{m}^{-2} \cdot \mathrm{d}^{-1}$, which is very close to the target estimated by the DOE for economic feasibility of microalgal biofuels.

This study contributes guidance for comprehensive resource assessment and techno-economic analyses of the potential of microalgal biotechnology according to the South American resources and specific needs.

\section{Experimental Section}

\subsection{Microalgal strain and culture conditions}

The microalgal strain used in this work was $S$. obliquus $\mathrm{C} 1 \mathrm{~S}$ was isolated from an artificial freshwater reservoir



S. obliquus $\mathrm{C} 1 \mathrm{~S}$ was routinely maintained in BG11 medium ${ }^{[39]}$ solidified with $1 \%$ (w/v) agar-agar. For the preparation of inoculums, $S$. obliquus cells were cultivated in $500 \mathrm{~mL}$ sterilized glass bottles containing 300 $\mathrm{mL}$ of modified BG11 medium supplemented with $6 \mathrm{mM} \mathrm{NaNO}_{3}$ as a $\mathrm{N}$ source and $0.42 \mathrm{~g} \cdot \mathrm{L}^{-1} \mathrm{NaHCO}_{3}$ to buffer $\mathrm{CO}_{2}$ supplementation. Cultures were sparged with filtered air containing $2 \%(\mathrm{v} / \mathrm{v}) \mathrm{CO}_{2}$ at $0.3-0.5$ $\mathrm{L} \cdot \mathrm{min}^{-1}$ at $29 \pm 1{ }^{\circ} \mathrm{C}$ under constant white light at $310 \mu \mathrm{mol}$ photons $\cdot \mathrm{m}^{-2} \cdot \mathrm{s}^{-1}$.

For cultivation in environmental photobioreactors, two Phenometrics ePBR laboratory benchtop photobioreactors ${ }^{[24]}$ were used. Initially, the ePBRs were inoculated with $S$. obliquus $\mathrm{C} 1 \mathrm{~S}$ at an $\mathrm{OD}_{750}$ of 0.3 and cells were acclimated at the testing weather-simulated conditions for one to two weeks depending on the apparent doubling time at the stated conditions. Then, cells were collected by centrifugation at $3,900 \times \mathrm{g}$ for $10 \mathrm{~min}$ and fresh medium was inoculated with acclimated cells at an initial $\mathrm{OD}_{750}$ of 0.3 for data collection. In addition to the magnetic bar of the ePBRs, sterile air was moistened in a water trap, to minimize evaporation, and bubbled at $0.3-0.5 \mathrm{~L} \cdot \mathrm{min}^{-1}$ to help achieving homogeneous mixing. When supplemented with $\mathrm{CO}_{2}$, BG11 medium additionally contained $0.42 \mathrm{~g} \cdot \mathrm{L}^{-1} \mathrm{NaHCO}_{3}$ to avoid sudden shifts in $\mathrm{pH}$, and the ePBRs were set to inject pure $\mathrm{CO}_{2}$ into the water trap for its dilution in air at an output concentration of $2 \%(\mathrm{v} / \mathrm{v}$ ) from $1 \mathrm{~h}$ after to $1 \mathrm{~h}$ before the light was switched on and off, respectively.

The simulated weather conditions are sown in Table 1. Raw data were obtained from the NASA Langley Research Center (LaRC) POWER Project funded through the NASA Earth Science/Applied Science Program (https://power.larc.nasa.gov/data-access-viewer/). The average maximum and minimum temperatures and mid-day irradiation in the Southern Hemisphere were calculated considering the mean values of each month and by pondering the number of days of that month in the season. Thus, mean values corresponded to 10 days of month 12, 31 days of month 1, 28 days of month 2, and 21 days of month 3 for summer; 10 days of month 3, 30 days of month 4, 31 days of month 5, and 21 days of month 6 for autumn; 9 days of month 6 , 31 days of month 7, 30 days of month 8, and 21 days of month 9 for winter; and 9 days of month 9,31 days of month 10, 30 days of month 11, and 21 days of month 12 for spring. Maximum irradiation at mid-day was estimated from daily total irradiation and average day length in each location and season.

When ponds' depth was simulated at $5 ; 10$; or $20 \mathrm{~cm}$, the corresponding volume and area exposed to light were 90 ; 200 ; or $460 \mathrm{~mL}$ or $25.78 ; 32.47$; or $36.78 \mathrm{~cm}^{2}$, respectively. In each case, the light irradiation on the culture's surface was calibrated according to the ePBR manufacturer's instructions.

\subsection{Analytical methods}

Most analytical methods were described previously by Coronel et al. ${ }^{[37]}$. Cell density was estimated by OD at $750 \mathrm{~nm}$ and biomass dry weight, which was determined by centrifugation of culture samples at $3,900 \mathrm{x}$ $g$ for 10 min and drying out the cell pellets in an oven at $70{ }^{\circ} \mathrm{C}$ until constant weight $(2-3$ days). For the determination of total biomass carbohydrates, samples were reacted with the anthrone reagent ${ }^{[40]}$ and carbohydrates content was calculated from a standard curve made of glucose. Lipids were determined by the sulfo-phospho-vanillin method ${ }^{[41]}$ using canola oil as a lipid standard.

\subsection{Calculations}

Fort the calculation of biomass productivity, cultures were run until they increased 2.5 - 4 times the initial 
$\mathrm{OD}_{750}$, making sure there were no signs of culture approaching the stationary phase of growth. This took as short as two days for the Fortaleza simulated-weather or as long as 7 days for Comodoro Rivadavia winter simulated-conditions. Adjustments were made in the calculations to subtract the inoculated biomass, medium volume and biomass removed, and evaporation at each data point. For evaporation rate, the height of the culture's surface was labeled in the ePBRs at each data point and the volumes were determined after removing the culture at the end of the run and adding known volumes of water to the vessels up to each label. The maximum evaporation rates (last sampling time points) across the study were 10-15\%, 25-30\%, or $30-33 \%$ for $20 \mathrm{~cm}-, 10-$, or $5 \mathrm{~cm}$-deep simulated ponds.

The biomass productivity was calculated as the dry-biomass produced during the elapsed time and the area exposed to light and expressed in $\mathrm{g} \cdot \mathrm{m}^{-2} \cdot \mathrm{d}^{-1}$. The productivity of lipids and carbohydrates was calculated essentially following the same criterion as that for biomass.

For the general model of South American mean annual biomass productivity depicted in Figure 1 the heat map was generated with Q-GIS 3.12 and the semi-empirical biomass productivities obtained by cultivating S. obliquus under climate-simulated conditions in ePBRs.

\section{Supporting information}

The online version contains Supplementary Information available at https://oi. org/

\section{Acknowledgements}

We are very thankful to Laura Zulaica for preparing the heat maps for the graphical abstract and Figure 1. C.D.C. is a doctoral fellow at the CONICET and L.C. is a career researcher at the CONICET, Argentina. This work was supported by Grants PICT2015 - 3559 and PICT2018 - 3382 from the Agencia Nacional de Promoción Científica y Tecnológica, Argentina to LC.

\section{Conflict of interest}

The authors declare no conflicts of interest.

\section{Authors' contributions}

C.D. Coronel: performed all the experiments, determinations and calculations, and reviewed and edited the draft manuscript; L. Curatti: conceptualized the study, provided supervision and funding, analyzed the results and wrote the manuscript.

\section{References}

[1] United Nations, United Nations Publication Issued by the Department of Economic and Social Affairs 2019 .

[2] F. W. Moejes, K. B. Moejes, African J. Biotechnol.2017 , 16,288

[3] S. Karekezi, W.Kithyoma, in Bioenergy and Agriculture: Promises and Challenges, Focus 14 (Eds: P. Hazell, R. K. Pachauri), International Food Policy Research Institute (IFPRI), Washington D. C., USA 2009 .

[4] E. S. Shuba, D. Kifle, Renew. Sust. Energ. Rev.2018, 81, 743.

[5] D. S. Kim, M. Hanifzadeh, A. Kumar, Environ. Prog. Sust. Energ. 2018 , 37 , 7.

[6] I. Rawat, R. Ranjith Kumar, T. Mutanda, F. Bux, Appl. Energ. 2011 , 88 , 3411.

[7] J. C. M. Pires, M. C. M. Alvim-Ferraz, F. G. Martins, M. Simões,Renew. Sust. Energ. Rev. 2012 , 16 , 3043.

[8] M. A. Borowitzka, M. A, J. Appl. Phycol. $1992,4,267$.

[9] P. J. L. B. Williams, L. M. L. Laurens, Energ. Environ. Sci. 2010 , 3 , 554. 
[10] F. G. Acién, E. Molina, J. M. Fernández-Sevilla, M. Barbosa, L. Gouveia, C. Sepúlveda, J. Bazaes, Z. Arbib, in Microalgae-Based Biofuels and Bioproducts: From Feedstock Cultivation to End-Products(Eds: C. Gonzalez-Fernandez, R. Muñoz), Woodhead Publishing, Cambridge, England 2017 , Ch. 20.

[11] E. R. Venteris, R. C. McBride, A. M. Coleman, R. L Skaggs, M. S. Wigmosta, Environ. Sci. Technol . $\mathbf{2 0 1 4}, 48,3559$.

[12] T. J. Lundquist, I. C. Woertz, N. W. T. Quinn, J. R. Benemann, Energy Biosciences Institute, University of California Berkeley2010 .

[13] M .E. Huntley, Z. I. Johnson, S. L. Brown, D. L. Sills, L. Gerber, I. Archibald, S. C. Machesky, J. Granados, C. Beal, C. H. Greene, Algal Res. 2015 , 10 , 249.

[14] R. Davis, J. Markham, C. Kinchin, N. Grundl, E. Tan, D. Humbird, Natl. Renew. Energy Lab. 2016.

[15] L. M. L. Laurens, IEA Bioenergy 2017

[16] P. J. Lammers, M. Huesemann, W. Boeing, D. B. Anderson, R. G. Arnold, X. Bai, M. Bhole, Y. Brhanavan, L. Brown, J. Brown, J. K. Brown, S. Chisholm, C. Meghan Downes, S. Fulbright, Y. Ge, J .E. Holladay, B. Ketheesan, A. Khopkar, A. Koushik, P. Laur, B. L. Marrone, J. B. Mott, N. Nirmalakhandan, K. L. Ogden, R. L. Parsons, J. Polle, R. D. Ryan, T. Samocha, R. T. Sayre, M. Seger, T. Selvaratnam, R. Sui, A. Thomasson, A. Unc, W. Van Voorhies, P. Waller, Y. Yao, J. A. Olivares, Algal Res. 2017, 22 , 166.

[17] Q. Béchet, A. Shilton, B. Guieysse, Biotechnol. Adv.2013 , 31 , 1648.

[18] J. W. Moody, C. M. McGinty, J. C. Quinn, Proc. Natl. Acad. Sci. 2014 , 111 , 8691.

[19] D. L. Angulo, G. Martínez, L. Mérida Ramírez, Rev. Venez. Cienc. Tecnol. Aliment. 2017 , 8 , 130.

[20] B. S. A. F. Brasil, F. C. P. Silva, F. G. Siqueira, New Biotechnol. 2017 , 39 , 90.

[21] M. Do Nascimento, J. C. F. Ortiz-Marquez, L. Sanchez-Rizza, M. M. Echarte, L. Curatti, Bioresour. Technol. $2012,125,283$.

[22] D. S. Andrade, T. S. Telles, G. H. Leite Castro, J. Clean. Prod. 2020 , 250 , 119526.

[23] M. Huesemann, T. Dale, A. Chavis, B. Crowe, S. Twary, A. Barry, D. Valentine, R. Yoshida, M. Wigmosta, V. Cullinan, Algal Res.2017, 21 , 178.

[24] B. F. Lucker, C. C. Hall, R. Zegarac, D. M. Kramer, Algal Res. 2014 , 6 , 242.

[25] M. Huesemann, A. Chavis, S. Edmundson, D. Rye, S. Hobbs, N. Sun, M. Wigmosta, J. Appl. Phycol. 2018, 30 (1), 287.

[26] S. F. Siqueira, M. M. Maroneze, R. R. Dias, R. G. Vendruscolo, R. Wagner, C. R. de Menezes, L. Q. Zepka, E. Jacob-Lopes, J. Chem. Technol. Biotechnol. 2020 , 95 , 2411.

[27] B. Soares-Filho, P. Moutinho, D. Nepstad, A. Anderson, H. Rodrigues, R. Garcia, L. Dietzsch, F. Merry, M. Bowman, L. Hissa, R. Silvestrini, C. Maretti, Proc. Natl. Acad. Sci. U. S. A.2010, 107 , 10821.

[28] T. de Marchin, M. Erpicum, F. Franck, J. Biotechnol.2015 , 215 , 2.

[29] Q. Zheng, X. Xu, G. J. O. Martin, S. E. Kentish, Chinese J. Chem. Eng . 2018 , 26 , 2219.

[30] Y. Chisti, Green 2013, 3, 195.

[31] M. Castillo, A. Martins, ECLAC-Prod. Dev. Ser.2016, 205.

[32] G. della Paolera, A. Musacchio, Natl. Bur. Econ. Res.2018 .

[33] H. Ritchie, M. Roser, Our World in Data 2020(Accessed on 6th June, 2020). 
[34] A. C. Apel, C.E. Pfaffinger, N. Basedahl, N. Mittwollen, J. Göbel, J. Sauter, T. Brück, D. Weuster-Botz, Algal Res.2017, 25, 381 .

[35] Y. Sui, Y. Jiang, M. Moretti, S. E. Vlaeminck, J. Clean. Prod. 2020 , 259 , 120782.

[36] M. H. Huesemann, J. Van Wagenen, T. Miller, A. Chavis, S. Hobbs, B. Crowe, Biotechnol. Bioeng. 2013 ,110(6), 1583.

[37] C. D. Coronel, M. Do Nascimento, L. Curatti, Bioresour. Technol. Reports 2019 , 5 ,104.

[38] J. C. F. Ortiz-Marquez, M. Do Nascimento, M. L. A. Dublan, L. Curatti, Appl. Environ. Microbiol. $2012,78,2345$.

[39] R. Rippka, J. Deruelles, J. B. Waterbury, M. Herdman, R. Y. Stanier, Microbiology 1979 , 111 , 1.

[40] R. Dreywood, Ind. Eng. Chem. Anal. Ed . $1946,18,499$.

[41] S. K. Mishra, W. I. Suh, W. Farooq, M. Moon, A. Shrivastav, M. S. Park, J. -W. Yang, Bioresour. Technol . $2014,155,330$.

Table 1 Climate-simulated conditions

Comodoro Rivadavia (AR)

Buenos Aires (AR)

Posadas (AR)

La Quiaca (AR)

Caracas

(VE)

Paita

$(\mathrm{PE})$

Fortaleza (BR)

Geographic coordinates

Geographic coordinates

4552'00"S 67deg30'00"W

34deg35'59"'S 58deg22'55"W

27deg22'00"S 55deg53'49"W

22deg06'20"S 65deg36'00"W

10deg30'00"N 66deg56'00"W

5deg04'00"S 81deg06'00"W

3deg46'53"S 38deg35'20"W

\section{Summer}

Temperature

$19+-6$

$24+-5$

$26+-6$ 


$$
\begin{aligned}
& 14+-7 \\
& 25+-5 \\
& 27+-4 \\
& 28+-3
\end{aligned}
$$

Max. irradiation

1353

1489

1430

1737

1451

1964

1554

Day duration

15

14

14

14

14

13

13

Culture depth

20

20

20

20

20

20

20,10 or 5

Autumn

Temperature

$16+-4$

$19+-6$

$12+-8$

$27+-3$ 
Max. irradiation

838

975

1501

1402

Day duration

$12^{\mathrm{g}}$

12

14

13

Culture depth

20

20

20

20

Winter

Temperature

$8+-4$

$13+-4$

$17+-6$

$11+-7$

$22+-5$

$23+-4$

$27+-4$

Max. irradiation

656

969

1007

1643

1504

1421

1719

Day duration

11 
Culture depth

20

20

20

20

20

20

20,10 or 5

\section{Spring}

Temperature

$20+-5$

$23+-6$

$14+-9$

$28+-3$

Max. irradiation

1713

1492

2133

1810

Day duration

14

14

12

13

Culture depth

20

20

20 
Temperature ( $\operatorname{deg} \mathrm{C})$; Max. Irradiation ( $\mu$ mol photons $\left.\cdot \mathrm{m}^{-2} \cdot \mathrm{s}^{-1}\right)$; Day duration $(\mathrm{h})$; Culture depth $(\mathrm{cm})$. Weather conditions were obtained from the NASA Langley Research Center (https://power.larc.nasa.gov/dataaccess-viewer/).

Comodoro Rivadavia (AR, Argentina); Buenos Aires (AR, Argentina); Posadas (AR, Argentina); La Quiaca (AR, Argentina); Caracas (VE, Venezuela); Paita (PE, Peru) and Fortaleza (BR, Brazil)

\section{Figure captions}

Figure 1. Potential microalgal biomass productivity in different ecoregions of South America. S. obliquus sp. C1S cultures simulating $20 \mathrm{~cm}$-deep ponds in simulated-climatic conditions in (A) Comodoro Rivadavia (AR); (B) Buenos Aires (AR); (C) Posadas (AR); (D) Caracas (VE); (E) Paita (PE); and (F) Fortaleza (BR). S, summer; W, winter. The heat map was generated with Q-GIS 3.12. Data represent the mean and range of two independent experiments.

Figure 2. Effect of $\mathrm{CO}_{2}$ supplementation on biomass productivity of $S$. obliquus sp. C1S. $20 \mathrm{~cm}$-deep ponds were simulated in summer or winter, under simulated-climatic conditions of Buenos Aires, Posadas and Fortaleza. Data represent the mean and range of two independent experiments.

Figure 3. Effect of $\mathrm{CO}_{2}$ supplementation on (A-B) carbohydrates or (D-D) lipids accumulation of S. obliquussp. C1S cultures in $20 \mathrm{~cm}$-deep simulated ponds in (A, C) summer or (B, D) winter climatic conditions of Fortaleza. Data represent the mean and range of two independent experiments.

Figure 4. Effect of culture depth on algal biomass productivity. A) S. obliquus sp. C1S cultivated in ePBRs. From left to right: 20 -cm deep culture, $\mathrm{OD}_{750} 0.3 ; 20$-cm deep culture, $\mathrm{OD}_{750} 1.5 ; 5$-cm deep culture, $\mathrm{DO}_{750}$ 1.5. B) Growth curves; C) volumetric biomass productivity; and (D) areal biomass productivity of $S$. obliquussp. C1S cultures simulating different pond's depth in summer (full circles) or winter (open circles) climate conditions in Fortaleza. Data represent the mean and standard error of six (winter, 5-cm ponds) or two (other) independent experiments.

Figure 5. Effect of culture depth on (A-B) carbohydrates or (C-D) lipids accumulation of S. obliquus sp. C1S cultures simulating 20-, 10- or 5-cm deep ponds in (A, C) summer or (B, D) winter climatic conditions of Fortaleza. Data represent the mean and standard error of four (5-cm deep ponds in winter) or two (other conditions) independent experiments.

Figure 6. Induction of lipids accumulation by $S$. obliquus sp. C1S in simulated 5-cm deep ponds in winter in Fortaleza. A) Growth curve; (B) lipids content on a dry weight biomass basis; and time course of (C) biomass; or (D) lipids areal productivity. Data represent the mean and range of two independent experiments. 

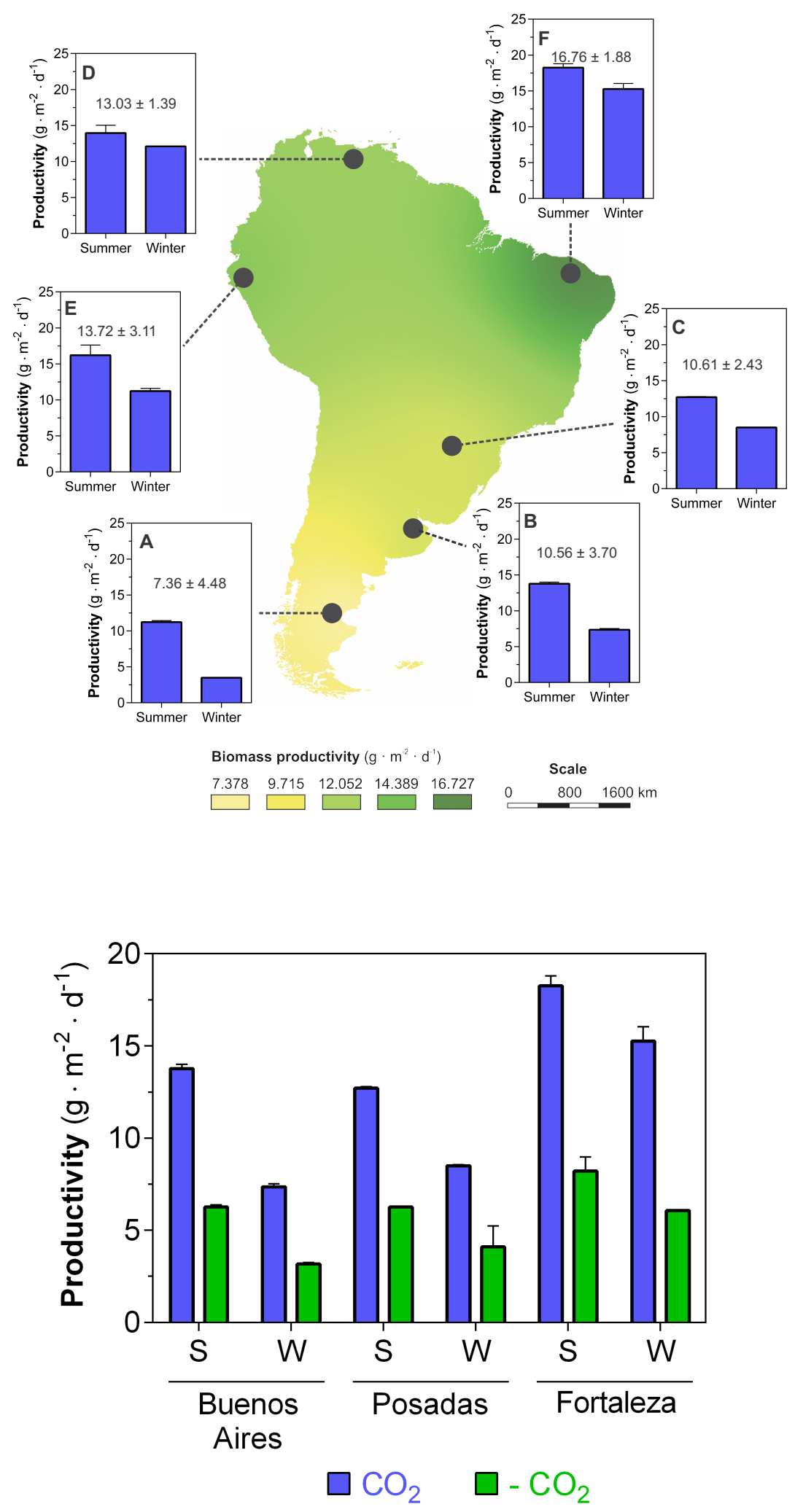
A

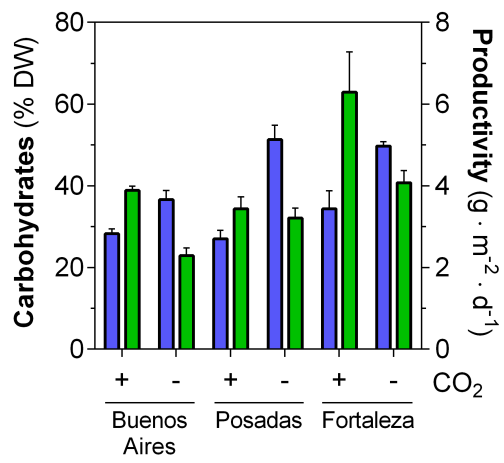

C

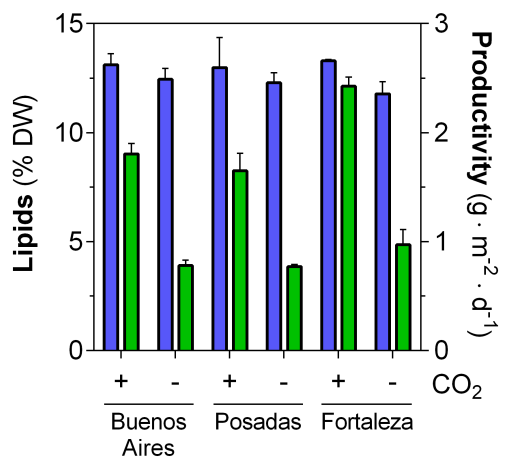

$\square$ Percentage

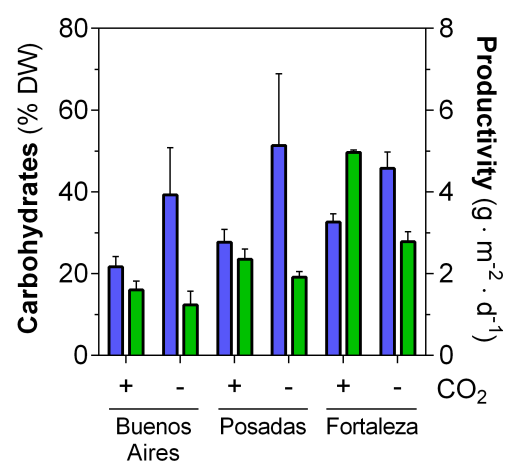

D

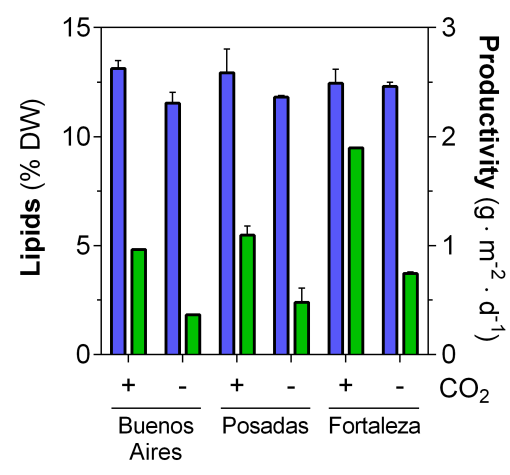


A

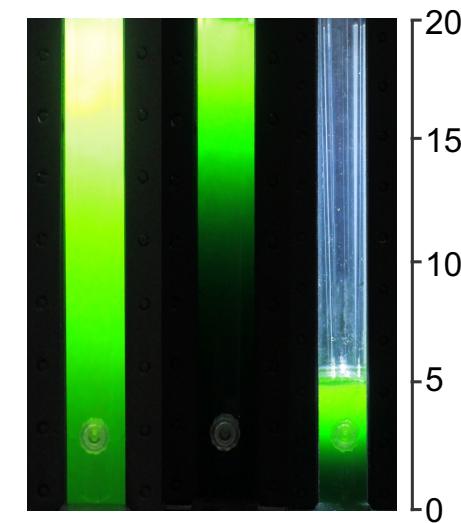

C

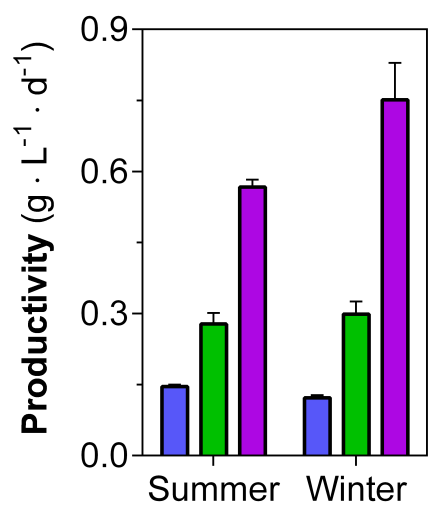

$20 \mathrm{~cm}$
B
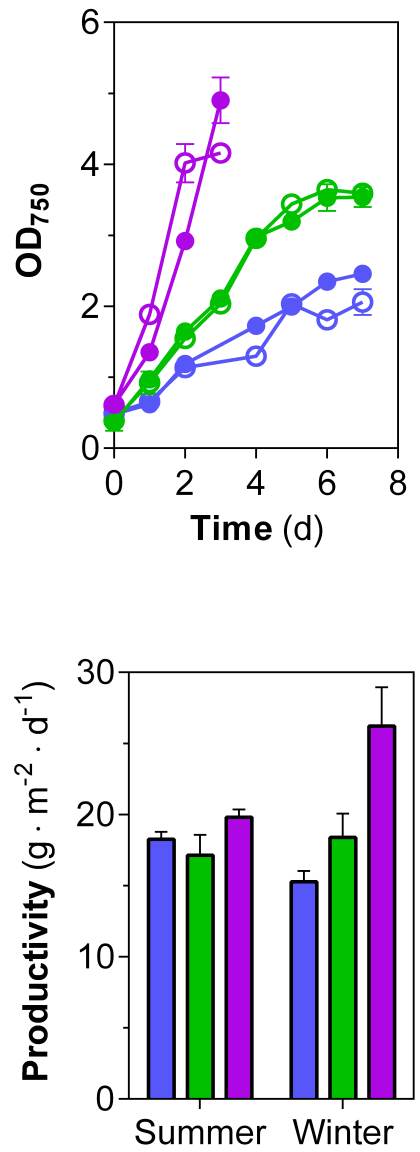

$10 \mathrm{~cm} \square 5 \mathrm{~cm}$ 
A

B
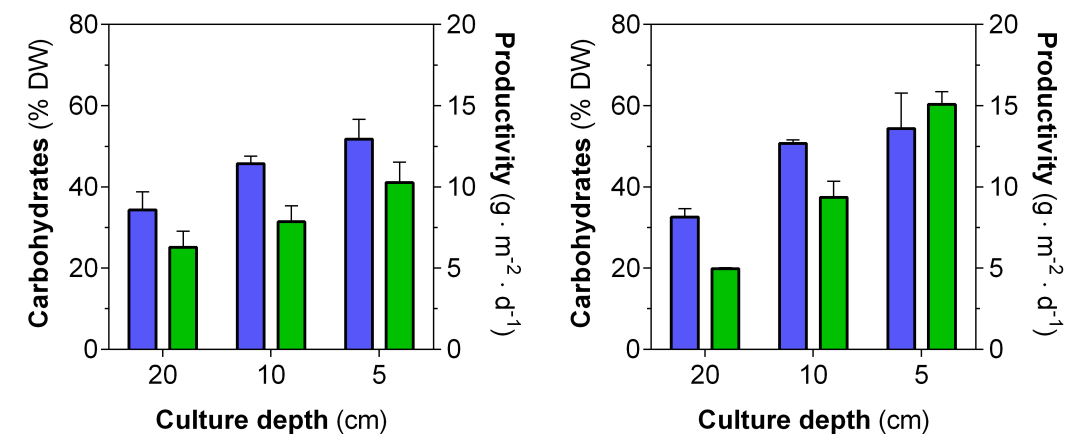

C
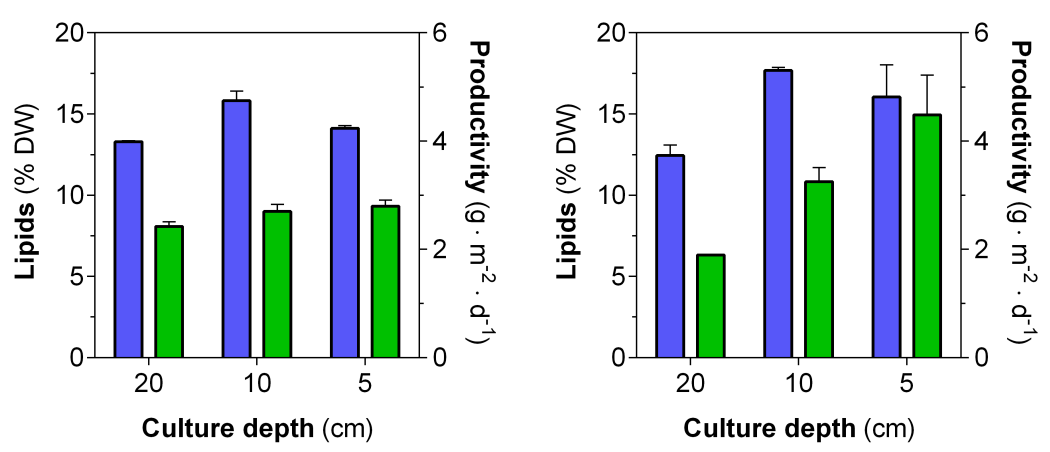

$\square$ Percentage

$\square$ Productivity 
A

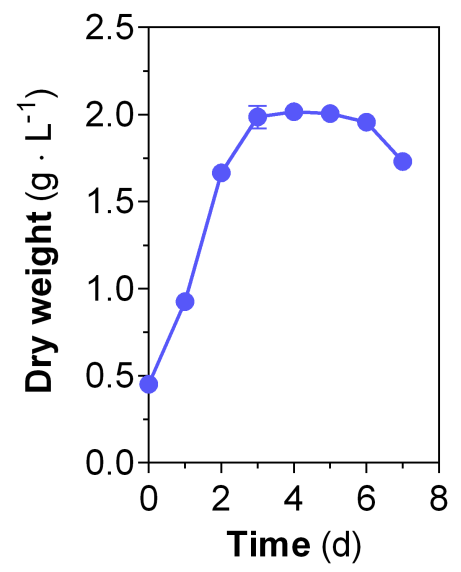

C

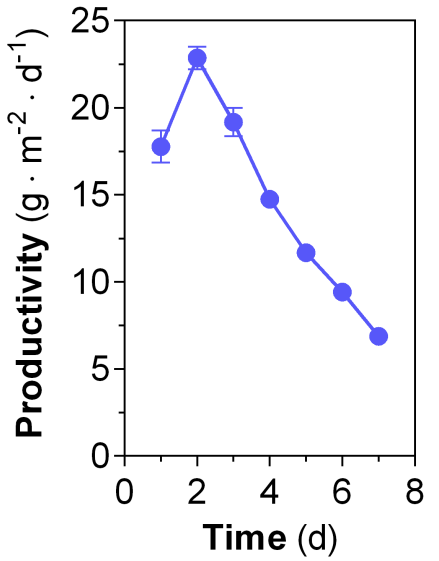

B

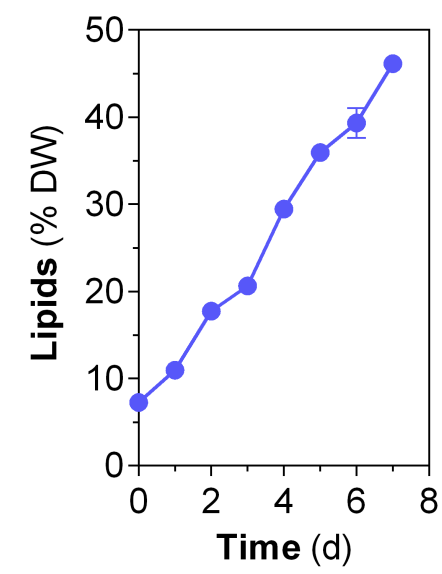

D

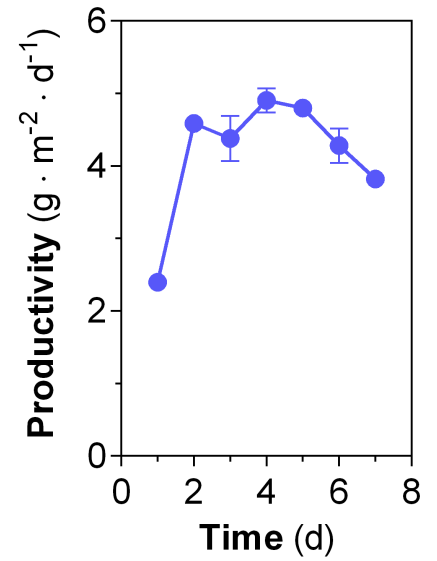

